\title{
Quality of basic emergency obstetric and newborn care (BEmONC) services from patients' perspective in Adigrat town, Eastern zone of Tigray, Ethiopia. 2017: a cross sectional study
}

\author{
Betell Berhane $^{1 *}$ (D), Haftom Gebrehiwot ${ }^{2}$, Solomon Weldemariam² ${ }^{2}$ Berhane Fisseha ${ }^{3}$, Samson Kahsay ${ }^{4}$ and
} Alem Gebremariam ${ }^{3}$

\begin{abstract}
Background: Most of the maternal and newborn deaths occur at birth or within $24 \mathrm{~h}$ of birth. Provision of quality Basic Emergency Obstetric and Neonatal Care (BEmONC) is very crucial and the current recommended intervention to prevent maternal and newborn morbidity and mortality.

Methods: An institution based cross-sectional study was conducted among mothers receiving at least one of the signal functions of BEmONC services. A total of 398 women were included in the study. The study participants were selected using a systematic random sampling method. Data was collected using structured interviewer-administered Tigrigna version questionnaire. Data were analyzed using SPSS version 20. Multi-variable logistic regression was used to control the effect of confounders.
\end{abstract}

Results: The perceived quality of BEmONC was $66.7 \%$, which is poor. Clients scored lower quality rates on aspects such as the availability of necessary equipment, lack of clean and functional shower and toilet and administration of antipain during delivery and manual vacuum aspiration (MVA). Quality of BEmONC was lower among rural residents (AOR $=0.273$, 95\% Cl: (0.151-0.830). Whereas, Presence of companion (AOR $=2.259 ; 95 \% \mathrm{Cl}$ : (3.563-13.452) were found with a higher score of quality of BEmONC compared to their counterparts.

Conclusion: The overall perception of quality of BEmONC services received was poor. Residence, ANC follow-up, and presence of companion during labor or delivery were found to have a significant association with the perceived quality of BEmONC services.

Keywords: Quality, Basic emergency obstetric and newborn care, Adigrat, Tigray, Ethiopia

\section{Background}

Worldwide, $15 \%$ of the expected births result in life-threatening complications during pregnancy, labor, delivery and post-partum period [1]. World Health Organization (WHO) designed and introduced Emergency Obstetric and Newborn Care (EmONC) to reduce maternal and infant mortality [2]. Though remarkable

\footnotetext{
* Correspondence: betiela03@yahoo.com

${ }^{1}$ Department of Midwifery, College of Medicine and Health Science, Adigrat University, Adigrat, Ethiopia

Full list of author information is available at the end of the article
}

changes have been recorded, maternal and neonatal mortality rates in Ethiopia are among the highest in the World [3] .

A set of seven key obstetric services, or "signal functions," has been identified as critical to basic emergency obstetric and newborn care (BEmONC): administration of parenteral antibiotics, administration of parenteral anticonvulsant, administration of parenteral uterotonic agents, removal of retained products (MVA), assisted vaginal delivery; manual removal of placenta and resuscitation of the newborn [4] . 
As an intervention, the Federal Ministry of Health of Ethiopia is implementing EmONC services. Provision of quality EmONC service is mandatory to achieve the stipulated goals in the sustainable development goals at reducing the maternal and new-born mortality in Ethiopia and worldwide. According to the Ethiopian health care transformation plan, the health system over the last two decades has been focused on improving coverage of essential health service. It is time to pay great attention to the quality and equity of health service at all levels of the system and a lot remains to be done toward improving quality of care at each level of health system [5].

Quality health service is multidirectional; Donabedian's theory incorporates participants rating in the advent of assessing the quality of health service delivered.

Taking into account the perspective of clients on the maternal and neonatal health care services enables to rate clients' satisfaction concerning the services received from the healthcare providers [6]. In Ethiopia, there are studies which assessed availability of EmONC services [3, 7-9]. However, there is sub-optimal knowledge of quality BEmONC service from the clients' perspective and experience [10]. Therefore, this study was conducted to describe the quality of BEmONC services and factors associated with it among mothers receiving these services. This will help to document the quality of EmONC service from the users' perspective which is important to develop client centered BEmONC guidelines.

\section{Methods}

\section{Study area and design}

The study was conducted in Ganta-Afeshum district, Eastern zone of Tigray which is located around $903 \mathrm{Ki}-$ lometers to the North of Addis Ababa, the capital city of Ethiopia. It is one of the rural districts of Eastern zone of Tigray. An institution based cross sectional study was conducted among women receiving BEmONC services in 2017.

\section{Sample size and sampling procedure}

A total of 398 women receiving BEmONC services were included in the study. The sample size was computed using a single population proportion formula considering $62 \%$ proportion of mothers satisfied with delivery services in a study conducted previously [8] 95\% confidence level, $5 \%$ margin of error and considering $10 \%$ of non-response rate.

There were three public health institutions providing BEmONC services in Adigrat during the data collection period, two health centres and one general hospital. All of these facilities were included in the study. Pre survey assessment was carried out to determine the average daily flow of mothers receiving the services in the hospital and health centers. Accordingly the expected number of attending women in the specified period of data collection, the sample size was proportionally allocated to the health centers and general hospital. Finally, individual study subject were selected from each facility by using systematic sampling techniques.

All women who were discharged after receiving at least one of the signal functions of BEmONC services were included in the study. However, eligible mothers who were referred to other health facilities or unable to respond for the questionnaire were excluded from the study.

\section{Data collection procedure}

Data collection tools were developed in English based on this study's objectives to be addressed after reviewing relevant literature $[11,9]$. The questionnaire was first prepared in the English language then translated to the local language, Tigrigna (also see Additional files $1 \& 2$ ). Back translation to English was also done by language experts to check its consistency. Three midwives with bachelors of Science (BSc) data collectors were recruited from Adigrat University as data collectors to fill the tools, and besides, one integrated emergency surgical officer was recruited to supervise the data collectors. Training was given to both the data collectors and the supervisor. The training focused on the objectives of the study, the data collection tool and procedures of the data collection and detailed contents of the tools. Further emphasis was given on the ethical issues of research and smooth and respect full approach with clients. The questionnaire was filled by face to face interaction with the clients after asking their willingness to participate in the study after briefly explaining its objective. Prior to implementation, the questionnaire was pretested and modifications made accordingly. Strict supervision was made by the supervisor and the principal investigator. Completed questionnaires were collected and assessed for consistency and completeness by the supervisor on daily basis.

\section{Operational definitions}

$>$ Quality- the extent to which health services for populations increased the likelihood of desired health outcomes and are consistent with current professional knowledge.

$>$ Magnitude of quality with the service: the responses "Strongly agree (very satisfied)" and "Agree (satisfied) " will be classified as agree (satisfied) and responses "strongly disagree (very dissatisfied)", "disagree (dissatisfied) " and "neutral" as disagree (unsatisfied). Neutral responses will be classified as disagree (dissatisfied) considering that they might represent a way of expressing dissatisfaction in a modest way. This 
Table 1 Socio-demographic characteristics of respondents in Adigrat, Eastern zone of Tigray, Ethiopia, 2017. ( $n=398)$

\begin{tabular}{|c|c|c|c|c|c|}
\hline Variable & Frequency & Percent (\%) & (Continued) & & \\
\hline Age of respondents & & & Variable & Frequency & Percent (\%) \\
\hline 15-19yrs & 23 & 5.8 & Un-employed & 9 & 2.4 \\
\hline $20-24 y r s$ & 103 & 25.9 & Farmer & 27 & 7.1 \\
\hline $25-29 y r s$ & 139 & 34.9 & Monthly HH income & & \\
\hline $30-34 y r s$ & 86 & 21.6 & 0-1500ETB & 76 & 19.04 \\
\hline$>35 y$ rs & 47 & 11.8 & 1501-3000ETB & 189 & 47.5 \\
\hline Residence & & & 3001-4500ETB & 75 & 18.8 \\
\hline Urban & 318 & 79.9 & 4501-6000ETB & 51 & 12.8 \\
\hline Rural & 80 & 20.1 & $>6000$ & 4 & 1.1 \\
\hline Religion & & & Unknown/Refusal & 3 & 0.75 \\
\hline
\end{tabular}

Orthodox

Muslim

Catholic

Ethnicity

Tigray

Afar

Amhara

Education

No formal education

1 to 6 th

7 th to 12 th

Certificate/Diploma

Degree and above

Occupation

Government employed
NGO/Private company employed
Merchant/business
House wife
Student
Marital status
Married
Unmarried
Husband's education

No formal education

1 to 6 th

7th to 12th

Certificate/Diploma

Degree and above

Husband's occupation

Governmental

NGO/Private company

Merchant/business man

Daily laborer

\section{8}

2.5

96

3

1
Table 1 Socio-demographic characteristics of respondents in Adigrat, Eastern zone of Tigray, Ethiopia, 2017. $(n=398)$

is likely because the interview is undertaken within the health facilities and mothers might be reluctant to express their dissatisfaction feeling of the services they received [9].

\section{Level of quality score in percentage}

Good quality- $75 \%$ and above.

Poor quality- $74.9 \%$ and below [9].

Patient perspective (experience) is feedback from patients on the course of receiving care or treatment, both the objective facts and their subjective views of it. The factual element is useful in comparing what people say they experienced against what an agreed care pathway or quality standard says should happen [12].

\section{Measurement of quality \\ Donabedian's framework}

The Donabedian's framework is based on three dimensions of quality; structure, process and outcome. These three are parameters from which inference can be drawn about quality of health care [6]. So, we used this framework to develop the questionnaire.

\section{Data analysis}

Data entry and clearing was done using Epi info. Data was analysed using statistical packages for social sciences version 20. Descriptive data analysis was done to describe the variables under study. Multivariable logistic regression analysis was done to see the independent effect of each variable on the outcome variable. Variables with $p$-value $<0.25$ in the bi-variate analysis were included in the multivariable analysis. Multi-colinearity was checked using the variance inflation factor (VIF), and those with VIF greater than 10 were excluded from the model. Result is presented using Adjusted Odds Ratio (AOR) with its 95\% Confidence Interval (CI). Significant association was declared at $p$ value $<0.05$. 
Table 2 Current obstetric history of patients receiving BEmONC services in Adigrat town, Eastern zone of Tigray, 2017. $(n=398)$

\begin{tabular}{lll}
\hline Variables & Frequency & $\%$ \\
\hline Gravidity & & \\
Primi & 336 & 84.4 \\
Multi & 62 & 15.6
\end{tabular}

\section{ANC follow-up}

Yes

No

Desire of current pregnancy

Wanted

Unwanted

Type of visit

Direct/ Planned

Referred

Mode of transportation

Ambulance

Public transportation

By foot

Time waited to receive service

$<15$ min

15-30 min

30 min-1 h

Presence of companion

Yes

No

Mode of delivery

$$
\text { SVD }
$$

AVD

Abortion

Health outcome of mother after delivery

Normal

With complication

Birth outcome of the neonate

$\begin{array}{ll}\text { Live birth } & 355 \\ \text { Neonatal death } & 7 \\ \text { Still birth } & 6 \\ \text { Health problem on neonate } & \end{array}$

\begin{tabular}{lll} 
No & 337 & 84.7 \\
Yes & 25 & 6.3 \\
Payment & & \\
No & 391 & 98.2 \\
Yes & 7 & 1.8 \\
\hline
\end{tabular}

77.9

22.1

\section{Ethical consideration}

Ethical clearance was obtained from Mekelle University College of health sciences institution review board (IRB) with serial No 046/09. Support letter was obtained from the Tigray Regional Health Bureau and Adigrat town health department and respective health institution to collect verbal data before field activities started. Verbal consent was obtained from the study subjects after explaining the study objectives and procedures. For the participants whose age is less than 18 years verbal informed consent was taken from their legal guardians. The participant's personal identification was not included in the study questionnaire to maintain anonymity. Confidentiality was maintained throughout the study.

\section{Results}

\section{Socio-demographic characteristics of respondents}

A total of 398 mothers fully responded to the interview making $100 \%$ response rate. Near three fourth (71.4\%) of the participants were from Adigrat general hospital. Majority $(59.8 \%)$ of the participants completed high school education ( 7 th to 12 th grade), Ninety five percent of the participants were currently married. The mean age of the mothers was 27.4 years with standard deviation of $( \pm 5.55)$ years (Table 1$)$.

\section{Current obstetric history of respondents}

Out of the 398 mothers, 336 (84.4\%) mothers had one to four pregnancies and $62(15.6 \%)$ mothers were grand multiparas having 5 to 8 pregnancies. Three hundred seventy-eight mothers had antenatal care (ANC) follow up. Eighty-eight $(22.1 \%)$ of the mothers were referred from other facilities. Spontaneous Vaginal Delivery (SVD) was the predominant mode of delivery (83.2\%). Out of the total births observed, 7 neonatal deaths and 6 still births were recorded (Table 2).

\section{Quality of BEmONC services from patients' perspective Structure}

When we see the overall mothers' perspective of quality in terms of input, $164(41.2 \%)$ mothers scored above $85 \%$ or stated it as good quality. Lack of necessary

Table 3 Input (structural) factors of quality of BEmONC, in Adigrat town, 2017. $(n=398)$

\begin{tabular}{lll}
\hline Variable & Good N (\%) & Poor N (\%) \\
\hline Necessary equipment availability & $278(69.8)$ & $120(30.2)$ \\
Adequate no of health providers & $327(82.2)$ & $71(17.8)$ \\
Sufficient rooms, beds and space & $344(86.4)$ & $54(13.6)$ \\
Sanitation & $344(86.4)$ & $54(13.6)$ \\
Functional and clean shower and toilet & $267(67.1)$ & $131(32.9)$ \\
\hline
\end{tabular}


Table 4 Process factor of quality of BEmONC in Adigrat town, 2017. $(n=398)$

\begin{tabular}{|c|c|c|}
\hline Variable & Good N (\%) & Poor N (\%) \\
\hline Respect and courtesy by the health providers & $383(96.2)$ & $15(3.8)$ \\
\hline The environment where you were laboring was comfortable. & $368(92.5)$ & $30(7.5)$ \\
\hline Active follow up on the progress of labor/abortion. & $368(92.5)$ & $30(7.5)$ \\
\hline Permission before applying any procedures and examination & $364(91.5)$ & $34(8.5)$ \\
\hline explained the labor progress to you by using your local and clear language & $351(88.2)$ & $47(11.8)$ \\
\hline different member of staff have given you similar advice or information & $367(92.9)$ & $31(7.1)$ \\
\hline Health workers spent enough time for examination. & $372(93.5)$ & $26(6.5)$ \\
\hline verbally encouraged praised and reassured & $387(97.2)$ & $11(2.8)$ \\
\hline got enough care and support during the time of labor. & $373(93.7)$ & $25(6.3)$ \\
\hline Confidence and competence of health providers & $379(95.2)$ & $19(4.8)$ \\
\hline Privacy well kept & $385(96.7)$ & $13(3.3)$ \\
\hline Got enough care and support during delivery/abortion & $384(96.7)$ & $13(3.3)$ \\
\hline Availability of health providers & $349(87.7)$ & $49(12.3)$ \\
\hline support from the staff in breast- feeding & $325(91.3)$ & $31(8.7)$ \\
\hline Received counseling on how to take care of your baby & $243(68.2)$ & $113(31.8)$ \\
\hline Your baby received enough care and support. & $316(90.5)$ & $43(9.5)$ \\
\hline Receive adequate anti pain while MVA was performed & $10(33.3)$ & $20(66.7)$ \\
\hline
\end{tabular}

equipment (30.2\%) was the major contributing factor for the reported poor quality of (Table 3 ).

\section{Process}

Mothers perspective of quality in terms of process, 180 (45.2\%) of them scored above $75 \%$ or stated as good quality. The major contributing factor for the poor quality was failure of health professionals to counsel the clients $(12.3 \%)$ on how to take care of their newborn baby (Table 4).

\section{Outcome (satisfaction)}

In the satisfaction section of the quality, 138 (34.7\%) mothers stated as good (satisfied). In this dimension of quality, the overall counseling that were given to patients and involving them in making decision contribute for the poor provision of quality of care (Table 5).

\section{The overall quality of BEmONC services from patients'} perspective

Quality in this study was assessed by combining the three dimensions the input, process and outcome. The quality is classified as good quality if it scored $75 \%$ and above. Otherwise it is classified as poor quality. The overall quality of BEmONC services from patients' perspective conducted in this study was $66.3 \%$ with $95 \% \mathrm{CI}$ (61.6, 71.4), $P$-value 0.04 .

\section{Factors associated with the quality of BEmONC services from patient's perspective}

On multi-variable, women who came from the rural area had lower odds of quality service $(\mathrm{AOR}=0.273$; $95 \% \mathrm{CI}$ : 0.15-0.83). On the other side, women who had ANC follow up had higher odds of quality BEmONC service $(\mathrm{AOR}=0.004) 95 \% \mathrm{CI}(0.091(0.011-0.723)$. Moreover,

Table 5 The output (satisfaction) factors of quality of BEmONC from patients' perspective, in Adigrat town, 2017. $(n=398)$

\begin{tabular}{|c|c|c|c|}
\hline $\mathrm{SNO}$ & Variable & Good N (\%) & Poor N (\%) \\
\hline 1 & Respect & $387(97.2)$ & $11(2.8)$ \\
\hline 2 & Professional respect for your privacy & $387(97.2)$ & $11(2.8)$ \\
\hline 3 & The number of health workers & $349(87.6)$ & $49(12.4)$ \\
\hline 4 & Health workers competency and confidence & $379(95.2)$ & $19(4.8)$ \\
\hline 5 & Communication between doctor, nurse and other health staff & $364(91.4)$ & $34(8.6)$ \\
\hline 6 & Involved you in decision & $352(88.7)$ & $45(11.3)$ \\
\hline 7 & The overall Counseling that were given in your stay. & $347(87.2)$ & $51(12.8)$ \\
\hline 8 & Overall care and support, given & $374(93.9)$ & $24(6.1)$ \\
\hline 9 & Care and support given for your newborn & $334(91.5)$ & $31(8.5)$ \\
\hline
\end{tabular}


Table 6 Association of quality of BEmONC services from patient's perspective in bivariate and multivariate analysis, in Adigrat town eastern zone of Tigray, 2017

\begin{tabular}{|c|c|c|c|c|c|c|}
\hline Variable & Good & Poor & COR & AOR & $\mathrm{Cl} 95 \%$ & $P$ value \\
\hline \multicolumn{7}{|l|}{ Residence } \\
\hline Urban & 222 & 96 & & 1.0 & & \\
\hline Rural & 42 & 38 & 0.47 & 0.273 & $0.15-0.83$ & $0.028 *$ \\
\hline \multicolumn{7}{|l|}{ Education } \\
\hline No formal education & 17 & 18 & 0.37 & 0.071 & $0.08-3.68$ & 0.54 \\
\hline 1 to 6 th & 41 & 21 & 0.78 & 0.334 & $0.16-4.97$ & 0.91 \\
\hline 7th to 12 th & 162 & 76 & 0.85 & 0.083 & $0.16-2.66$ & 0.56 \\
\hline Certificate/Diploma & 29 & 13 & 4.00 & 2.303 & $0.39-21.5$ & 0.18 \\
\hline Degree and above & 15 & 6 & & 1.0 & & \\
\hline \multicolumn{7}{|l|}{ Husband's education } \\
\hline No formal education & 23 & 19 & & 1.0 & & \\
\hline 1st to 6th & 23 & 17 & 0.47 & 0.060 & $0.20-5.36$ & 0.950 \\
\hline 7th to 12 th & 106 & 39 & 0.53 & 1.207 & $0.10-1.63$ & 0.206 \\
\hline Certificate/Diploma & 59 & 25 & 1.07 & 0.683 & $0.25-1.88$ & 0.478 \\
\hline Degree and above & 48 & 19 & 0.72 & 0.912 & $0.13-2.63$ & 0.209 \\
\hline \multicolumn{7}{|l|}{ Husband's Occupation } \\
\hline Governmental & 86 & 37 & & 1.0 & & \\
\hline NGO & 8 & 5 & 1.36 & 0.61 & $0.20-5.36$ & 0.950 \\
\hline Private(merchant) & 110 & 45 & 0.94 & 0.402 & $0.10-1.63$ & 0.206 \\
\hline Daily laborer & 32 & 19 & 1.43 & 1.88 & $0.25-1.88$ & 0.478 \\
\hline Unemployed & 6 & 3 & 0.99 & 0.410 & $0.13-1.56$ & 0.209 \\
\hline Farmer & 17 & 10 & 1.17 & 0.764 & $0.20-5.36$ & 0.875 \\
\hline \multicolumn{7}{|l|}{ Gravidity } \\
\hline Primi-gravida & 228 & 108 & 0.91 & 0.957 & $0.377-1.141$ & 0.837 \\
\hline Multi-gravida & 36 & 26 & & 1 & & \\
\hline \multicolumn{7}{|l|}{ ANC Follow-up } \\
\hline Yes & 254 & 124 & 2.04 & 0.004 & $0.01-0.72$ & $0.000 *$ \\
\hline No & 10 & 10 & & 1.0 & & \\
\hline \multicolumn{7}{|c|}{ Wanted status of pregnancy } \\
\hline Wanted & 241 & 104 & 3.02 & 0.946 & $0.59-3.80$ & 0.952 \\
\hline Unwanted & 23 & 30 & & 1.0 & & \\
\hline \multicolumn{7}{|l|}{ Type of visit } \\
\hline Planned(direct) & 216 & 94 & 1.91 & 0.520 & $0.24-1.08$ & 0.083 \\
\hline Referred & 48 & 40 & & 1.0 & & \\
\hline \multicolumn{7}{|l|}{ Presence of companion } \\
\hline Yes & 136 & 19 & 6.43 & 2.259 & $3.56-13.4$ & $0.002 *$ \\
\hline No & 128 & 115 & & 1.0 & & \\
\hline \multicolumn{7}{|l|}{ Mode of delivery } \\
\hline SVD & 240 & 91 & 4.55 & 1.692 & 0.110 & 0.641 \\
\hline AVD & 13 & 24 & 0.93 & 0.632 & 0.039 & 0.938 \\
\hline Abortion & 11 & 19 & & 1.0 & & \\
\hline \multicolumn{7}{|c|}{ Health outcome of the mother } \\
\hline Normal & 241 & 99 & 3.704 & 0.232 & $1.191-4.998$ & 0.519 \\
\hline With complication & 23 & 35 & & 1.0 & & \\
\hline
\end{tabular}


Table 6 Association of quality of BEmONC services from patient's perspective in bivariate and multivariate analysis, in Adigrat town eastern zone of Tigray, 2017 (Continued)

\begin{tabular}{|c|c|c|c|c|c|c|}
\hline Variable & Good & Poor & COR & AOR & $\mathrm{Cl} 95 \%$ & $P$ value \\
\hline \multicolumn{7}{|c|}{ Birth outcome of the neonate } \\
\hline Live birth & 248 & 107 & 0.245 & 1.184 & $0.02-1.6$ & 0.995 \\
\hline Neonatal death & 2 & 5 & 0.772 & .886 & $0.35-3.31$ & 0.956 \\
\hline Still birth & 3 & 3 & & 1.0 & & \\
\hline \multicolumn{7}{|c|}{ Health problem on neonate } \\
\hline Yes & 16 & 9 & 4.555 & 0.019 & 0.110 & 0.223 \\
\hline No & 235 & 102 & 0.936 & 0.134 & 0.039 & 0.083 \\
\hline \multicolumn{7}{|c|}{ Any payment for the servicea } \\
\hline Yes & 3 & 4 & 0.374 & 1.433 & $0.21-11.1$ & 0.571 \\
\hline No & 261 & 130 & & 1.0 & & \\
\hline \multicolumn{7}{|c|}{ Necessary equipment availability } \\
\hline Agree & 199 & 65 & 1.765 & 1.399 & $0.70-2.64$ & 0.291 \\
\hline Disagree & 85 & 49 & & 1.0 & & \\
\hline \multicolumn{7}{|c|}{ Adequate no of health providers } \\
\hline Agree & 35 & 12 & 0.956 & 0.879 & $0.188-1.067$ & 0.082 \\
\hline Disagree & 229 & 122 & & 1.0 & & \\
\hline \multicolumn{7}{|c|}{ Sufficient rooms, beds and space } \\
\hline Agree & 204 & 60 & 1.898 & 1.891 & $0.972-4.157$ & 0.060 \\
\hline Disagree & 86 & 48 & & 1.0 & & \\
\hline \multicolumn{7}{|c|}{ Functional and clean shower and toilet. } \\
\hline Agree & 65 & 49 & 1.649 & 0.971 & $0.822-2.96$ & 0.191 \\
\hline Disagree & 199 & 85 & & 1.0 & & \\
\hline \multicolumn{7}{|c|}{ Permission before applying any procedures and examination } \\
\hline Agree & 247 & 17 & 1.831 & 1.528 & $0.545-4.27$ & 0.420 \\
\hline Disagree & 119 & 15 & & 1.0 & & \\
\hline \multicolumn{7}{|c|}{ verbally encouraged praised and reassured } \\
\hline Agree & 253 & 10 & 0.355 & 0.291 & $0.041-2.465$ & 0.254 \\
\hline Disagree & 132 & 2 & & 1.0 & & \\
\hline \multicolumn{7}{|c|}{ Confidence and competence of health providers } \\
\hline Agree & 251 & 13 & 3.387 & 1.587 & $0.519-5.29$ & 0.266 \\
\hline Disagree & 114 & 20 & & 1.0 & & \\
\hline \multicolumn{7}{|l|}{ Privacy well kept } \\
\hline Agree & 257 & 7 & 1.323 & 6.911 & $0.673-12.7$ & 0.082 \\
\hline Disagree & 129 & 5 & & 1.0 & & \\
\hline \multicolumn{7}{|c|}{ Received counseling on how to take care of your baby } \\
\hline Agree & 170 & 94 & 1.464 & 1.51 & $0.938-2.33$ & 0.068 \\
\hline Disagree & 65 & 69 & & 1.0 & & \\
\hline \multicolumn{7}{|c|}{ Receive adequate anti pain while MVA was performed } \\
\hline Agree & 24 & 240 & 0.746 & 1.597 & $0.812-3.14$ & 0.175 \\
\hline Disagree & 18 & 116 & & 1.0 & & \\
\hline \multicolumn{7}{|c|}{ Respect and courtesy from the health professionals } \\
\hline Satisfied & 258 & 6 & 2.250 & 1.988 & $0.267-15.97$ & 0.377 \\
\hline Dissatisfied & 130 & 4 & & 1.0 & & \\
\hline
\end{tabular}

The boldface with asterisk [*] entries show the variables that have a significant association with the quality of BEmONC services from patients perspective in Adigrat town, Eastern zone of Tigray, Ethiopia 
those mothers who were accompanied by their relatives during their labor were with 7 times higher odds of good quality BEmONC service $(\mathrm{AOR}=6.9 ; 95 \% \mathrm{CI}$ : $(6.923$ (3.563-13.452) compared to their counterparts (Table 6).

\section{Discussion}

The overall magnitude of good quality from patients' perspective was $66.7 \%$ with $95 \%$ CI $(61.6,71.4)$.This result was comparable with the study conducted in Northern region of Ethiopia on the perceived quality of delivery and newborn care services which was $65.62 \%$ [11].

Providing quality service is not optional, it is a must to decrease the complications and mortality of the mother as well as their newborn babies. However, a significant number of women rated the service as poor. Lack of the necessary equipment and the quality of counseling on caring for the newborn baby was among the major components poorly addressed in the BEmONC service. Clients could not rely on or be satisfied with a health institution which could not fulfill equipment necessary for the services. After delivery, mother's attention and care is for her newborn and most of the time women who do not have the experience depend on health providers to give them information on how to take of their newborns. But failure to give this information will have a negative effect for the mothers' rating on the quality of service. On the contrary, patients experienced higher quality on how the health providers verbally encouraged them during labor pain.

Rural residents were at lower odds of perceived quality of BEmONC service. This could be explained by the difference in the level of expectations between the urban and rural residents. Residence has significant association with the quality in this study. This shows that women who live in urban residence have 53 times higher odds of receiving good quality service compared with those coming from rural residence; this result could be due to decreased level of expectation than those who live urban.

ANC follow up had significant association with the quality of the services $(p \leq 0.001)$ showing that women who did not have ANC follow-up score the quality 96 times higher than those who had the follow-up. This response could be because mothers who had the follow-up are aware of the care that is given during delivery because they are counseled during the follow-up, so they tend to score the quality higher. Similarly a study conducted in rural Tanzania shows there is a significance association with the perceived quality of care $(p=0.004)$ [13].

Women who were accompanied by their relatives were with 7 times higher odds of receiving good perceived quality service. This was also documented in other study where women who had continuous support from their relatives during labor and delivery were more likely to be satisfied than women who did not have support $[14,15]$.

\section{Limitation of the study}

$\triangleright$ Using only one method to assess the quality of the service, that is based on the response of the clients alone which may be affected by the social desirability bias and interviewers bias.

$>$ The study being in the health institution might give response favoring the care providers.

$>$ The cross sectional nature of the study makes difficult to establish the cause and effect relationship between the perceived quality and explanatory variables.

\section{Conclusion}

This study revealed that the overall quality of BEmONC services from patients' perspective was poor. Clients scored lower quality rates on aspects such as availability of necessary equipment, lack of clean and functional shower and toilet and administration of anti-pain during labor and MVA are some of the factors.

Though it is in line with the available literatures, significant number of the women rated the quality of service poor indicating mismatch between the participants' expectation and service delivered by the providers. Rating the service as poor was higher among rural resident women. On the contrary, good quality rating was higher among those women who had ANC and were accompanied by their relatives during their labor. Lower rate of quality was reported on the availability of equipment, and client provider communication.

\section{Additional files}

Additional file 1: English questionnaire. This data contains a brief description of the study and information for the study participants and legal guardians. (DOCX 25 kb)

Additional file 2: Tigrigna questionnaire, The English version questionnaire was later translated to the local language Tigrigna. (DOCX $31 \mathrm{~kb})$

\section{Abbreviations}

AOR: Adjusted odds ratio; BEmONC: Basic Emergency Obstetric and Newborn Care; COR: Crude odds ratio; EDHS: Ethiopia Demographic Health Survey; EMOC: Emergency Obstetric Care; HSDP: Health System Development Plan; HSTP: Health System Transformation Plan; MDG: Millennium Development Goals; MMR: Maternal Mortality Ratio; QOC: Quality of care; UNFPA: United Nations Population Fund; UNICEF: United Nations Children's Fund; WHO: World Health Organization

\section{Acknowledgements}

We would like to extend our gratefulness to Mekelle University for funding this research project. We would like to extend our heartfelt thanks to Tigray Regional Health Bureau for allowing us to conduct this study in Adigrat District. We also would like to acknowledge Adigrat District health office for their cooperation and giving all the necessary information. Our appreciation 
and thanks is also forwarded to all supervisors and data collectors of this study, as well as the study participants for their cooperation and providing us relevant information.

\section{Funding}

Mekelle University provided the financial support. The funding organization has no role in design of the study, data collection, analysis, and interpretation of data and in writing the manuscript.

\section{Availability of data and materials}

The datasets during and/or analyzed during the current study is available from the corresponding author on reasonable request.

\section{Authors' contributions}

BB carried out the conception and designing the study, performed statistical analysis and wrote the manuscript. BF performed statistical analysis. BB, SW, $H G, B F, A G$, and SK critically evaluated and made progressive suggestions throughout the study. All of the authors read and approved the final draft of the manuscript.

\section{Authors' information}

BB (MSc. In Midwifery), Lecturer in Adigrat University, SW (MSc. In Maternity and $\mathrm{RH}$ ), HG (MSc in Maternity and RH) PhD candidate at Mekelle University, BF (MPH in Epidemiology and Biostat), SK (MSC in IESO), AG (MPH in Epidemiology), PhD candidate at Addis Ababa University

\section{Ethics approval and consent to participate}

Ethical approval was obtained from Mekelle University ethical clearance committee and oral informed consent was taken from the study participants. Verbal consent was obtained from the study subjects after explaining the study objectives and procedures. For the participants whose age is less than 18 years verbal informed consent was taken from their legal guardians.

\section{Consent for publication}

Not applicable.

\section{Competing interests}

The authors declare that they have no competing interests.

\section{Publisher's Note}

Springer Nature remains neutral with regard to jurisdictional claims in published maps and institutional affiliations.

\section{Author details}

'Department of Midwifery, College of Medicine and Health Science, Adigrat University, Adigrat, Ethiopia. ${ }^{2}$ Department of Midwifery, College of Health Science, Mekelle University, Mekelle, Ethiopia. ${ }^{3}$ Department of Public health, College of Medicine and Health Science, Adigrat University, Adigrat, Ethiopia. ${ }^{4}$ Edagahamus Health Center, Eastern Zone of Tigray, Tigray, Ethiopia.

Received: 7 June 2018 Accepted: 22 April 2019

Published online: 30 May 2019

\section{References}

1. Al-Abri R, Al-Balushi A. Patient satisfaction survey as a tool towards quality improvement. Oman Med J. 2014;29(1):3-7. https://doi.org/10.5001/omj. 2014.02

2. Shalik R, Madhu K, Aro AR. Clients' Perspectives on the Quality of Maternal and Neonatal Care in Banke, Nepal. Health Sci J. 2015;9(2):10 ISSN 1791-809X.

3. Azmeraw T, Desalegn T, Kebede Y. Mothers' satisfaction with referral hospital delivery service in Amhara region, Ethiopia. BMC Pregnancy Childbirth. 2011;11:78.

4. Federal Democratic Republic of Ethiopia Ministry of Health: Basic emergency obstetric and newborn care training manual, 2013.

5. Federal Democratic Republic of Ethiopia Ministry of Health. Health Sector Transformation Plan, 2015 2015/16-2019/20(2008-2012 EFY)

6. Donabedian A. The definition of quality and approach to its measurement volume 1 exploration in quality assessment and monitoring; 1980.
7. Tadelle M, Yirgu G, Daniel B, Deregje H. Assessment of client satisfaction in labour and delivery service at maternity referral hospital in Ethiopia. Pan Afr Med J. 2014;17:76

8. Amdemichael R, Tafa M, Fekadu H. Maternal satisfaction with the delivery Services in Assela Hospital, Arsi zone, Oromia Region 2014. Gynecol Obstet (Sunnyvale). 4:257. https://doi.org/10.4172/2161-0932.1000257.

9. Yohannes B, Tarekegn M, Paulos W. Mothers utilization of antenatal care and their satisfaction with delivery services in selected public health facilities of wolaita zone, southern Ethiopia. Int J Sci Technol Res. 2013;2(2).

10. Wiegers TA. The quality of maternity care services as experienced by women in the Netherlands. BMC Pregnancy and Childbirth. 2009:9:18. https://doi.org/10.1186/1471-2393-9-1.

11. Girmatsion F, Yemane B, Alemayehu W, et al. Quality of delivery services in health facilities in northern Ethiopia. BMC Health Serv Res. 2017;17(1):187. https://doi.org/10.1186/s12913-017-2125-3.

12. Carlos H, Diaz S. Quality of care in family planning client need and providers need. Adv Contracept. 1993:9(2):129-39.

13. Eliyasiya $\mathrm{SH}$, Angela $\mathrm{K}$, et al. Determinant of perceived quality of obstetric care in rural Tanzania across sectional study. BMC Health Serv Res. 2014:14:483.

14. Iliadou M. Supporting women in labor. Health Sci J. 2012;6(3).

15. Odalea B, Mary P, Maria O e a. Support to women by a companion of her choice during child birth. Biomed Cent. 2007.

\section{Ready to submit your research? Choose BMC and benefit from:}

- fast, convenient online submission

- thorough peer review by experienced researchers in your field

- rapid publication on acceptance

- support for research data, including large and complex data types

- gold Open Access which fosters wider collaboration and increased citations

- maximum visibility for your research: over $100 \mathrm{M}$ website views per year

At BMC, research is always in progress.

Learn more biomedcentral.com/submissions 